\title{
THE COMMON CARDIAC VENTRICLE WITH TRANSPOSITION OF THE GREAT VESSELS*
}

\author{
BY \\ LARRY P. ELLIOTT, RAY C. ANDERSON, AND JESSE E. EDWARDS \\ From the Departments of Pediatrics and Pathology, University of Minnesota, Minneapolis, \\ and the Department of Pathology, The Charles T. Miller Hospital, St. Paul, Minnesota, U.S.A.
}

Received December 27, 1962

The physician dealing with congenital cardiac disease is not unlikely to be confronted with cases in which there is an abnormal relation between the great vessels (transposition). In analysing such a case, he attempts to determine whether or not there is some obstruction to pulmonary flow, and furthermore whether or not two ventricles are present, and, if so, which artery arises from which ventricle. At times, there is clear clinical evidence for the presence of one ventricle (common ventricle) with both great arteries arising from it. At other times, however, determination as to the existence of one or two ventricles is difficult, but whenever the two great vessels are transposed, one should suspect the presence of a common ventricle. Once this is established, either with or without pulmonary arterial obstruction, the nature of the atrio-ventricular $(\mathrm{A}-\mathrm{V})$ valves must be determined. In some cases of common ventricle there are two near-normal atrio-ventricular valves, while in others there is significant malformation of these valves: the latter malformations include common A-V valve and atresia either of the mitral or tricuspid valves.

\section{METHODS}

In the combined pathological collections of the University of Minnesota and the Cardiovascular Registry of The Charles T. Miller Hospital (totalling over 800 specimens with cardiac malformations) there are 26 examples of common ventricle with transposition. Each of these 26 specimens was examined with particular reference to the following factors: (1) the position of origin of the aorta with respect to the outflow part of the common ventricle and to the origin of the pulmonary trunk, (2) the nature of the pulmonary valve and subpulmonary region of the ventricle with particular emphasis on whether or not an obstructive lesion was present, and (3) the nature of the A-V valves.

The purposes of this study were to determine, in cases of common ventricle, whether or not a particular position of the origin of the aorta tends to be associated with (1) obstruction to pulmonary blood flow and (2) with a particular state of the A-V valves, and also whether those cases with obstruction to pulmonary flow differ in their association with malformations of the A-V valves when compared with cases with no pulmonary stenosis. Before describing the results, certain definitions are appropriate.

The common ventricle denotes one ventricular chamber into which both A-V valves (when there are two) empty. The same chamber gives rise to the pulmonary trunk and, usually through its fundibular portion, to the aorta. The infundibular chamber is a subdivision of the common ventricle. Lying anteriorly at the basal portion of the ventricle, the chamber communicates with the main part of the common ventricle below, and with the aorta above. The A-V valves do not communicate with the infundibular chamber.

The infundibulum, located at the base of the heart, lay in one of two positions. When the infundibulum was located at the right aspect of the base of the heart and its channel directed upward and to the left, it was

\footnotetext{
* This study was supported by Research grant HE-5694 of the National Heart Institute, United States Public Health Service. 


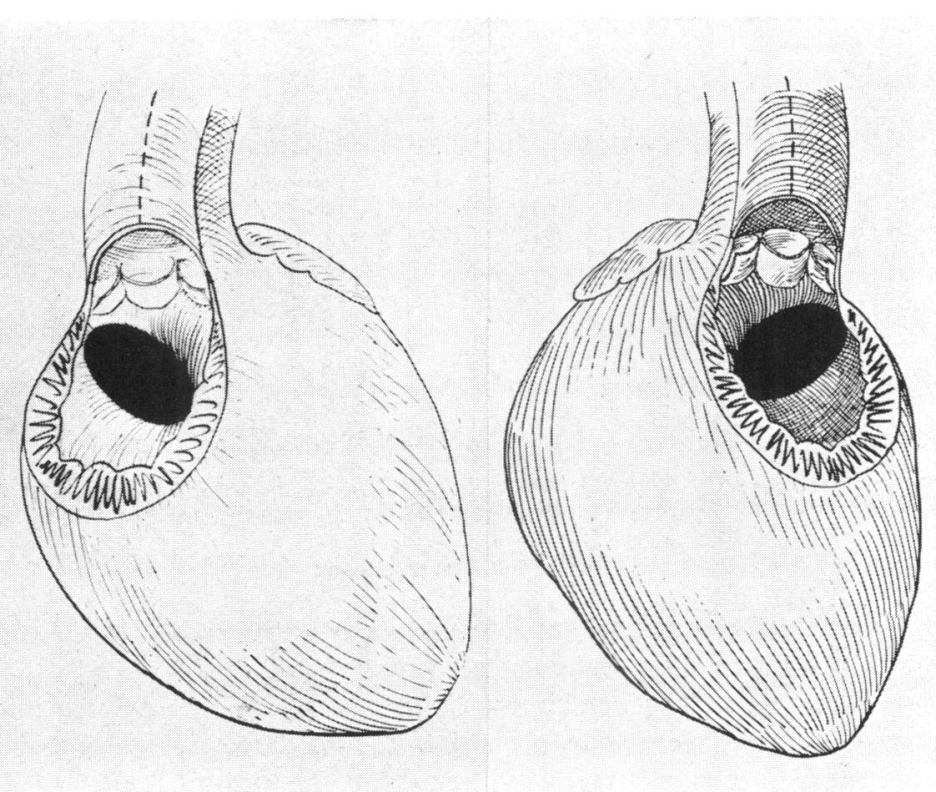

FIG. 1.-Diagrammatic representation of common ventricle with transposition showing the two positions occupied by the infundibulum. Left. The infundibulum is located at the right side of the base of the heart in the socalled "non-inverted" position. The transposed aorta arises from the infundibulum, and the pulmonary trunk, which is posterior and to the left of the aorta, arises from the main portion of the common ventricle. The latter structure is not shown. Right. The infundibular chamber is at the left side of the base of the heart, and is occupying an "inverted" position. Inversion of the infundibulum is a mirror image of the state of "non-inversion". The transposed aorta arises from the infundibulum, and the pulmonary trunk, which is posterior and to the right of the aorta, arises from the common ventricle. The latter is not shown in the diagram.

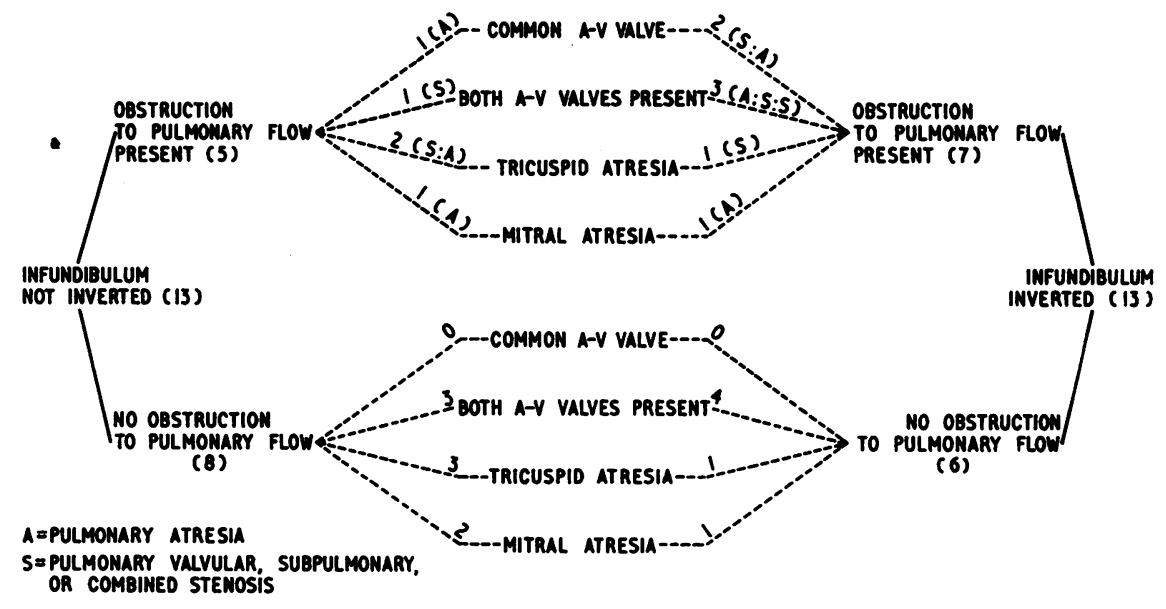

FIG. 2.-Distribution of 26 cases of common ventricle with transposition of the great vessels according to association with infundibular inversion, pulmonary stenosis, and state of the atrio-ventricular valves. 
considered to be "non-inverted" (non-inversion of the infundibulum; Fig. 1, left). When the infundibulum was located at the left aspect of the base of the heart, its channel being directed upward and toward the right, it was considered as "inverted" (Fig. 1, right). When the infundibulum was "non-inverted", the anatomical pattern corresponded to Type 4 (mixed) transposition of Spitzer; when inverted, the anatomical pattern was the "inverted" form of Type 4 of Spitzer (1951). The designation of the infundibular chamber as "inverted" and "non-inverted" seemed appropriate, since the inverted type may be considered as a mirror image of the non-inverted type.

Other investigators have variously called this structure the rudimentary (Favorite, 1934; Campbell, Reynolds, and Trounce, 1953; Heath, 1957; Taussig, 1960), supplementary (Abbott, 1936), basilar outflow (Rogers and Edwards, 1951), bulbar (Harley, 1958), sub-aortic compartment (Edwards, 1960), and outlet (Lev, Alcalde, and Baffes, 1961) chamber of a common ventricle.

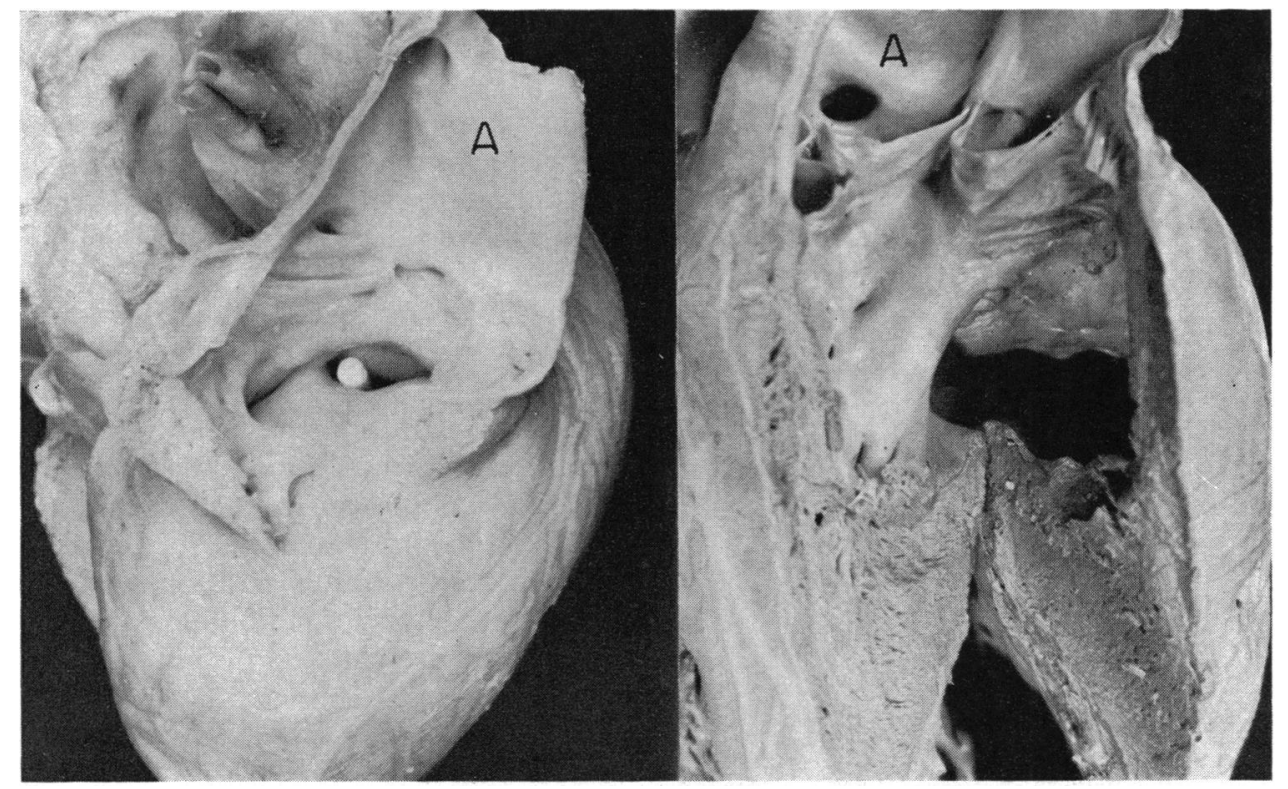

Fig. 3.-The interior of the infundibulum in two cases. Left. Right anterior oblique view of the heart: the infundibulum is non-inverted and shows internal features like those of the right ventricular infundibulum of normal hearts. The aorta arises from it. The communication between the infundibulum and the main part of the common ventricle (probe) is relatively narrow. Right. Left anterior oblique view: the infundibulum is inverted. The transposed aorta (A) arises from the infundibulum. The communication between the infundibulum and common ventricle is relatively wide.

\section{RESULTS}

Infundibulum. In each of the 26 examples of common ventricle with transposition studied, an infundibular chamber was present. In one-half $(13$ cases) the infundibulum was inverted (Fig. 2), and in the other half it was non-inverted (Fig. 1 and 2). Regardless of its position, the infundibular chamber had internal features like those of the outflow tract of the right ventricle of normal hearts (Fig. 3). Considerable variations existed in the calibre of the lower opening of the infundibular chamber, and in some it was sufficiently narrow to cause sub-aortic stenosis (Fig. 3, left).

Relation of Great Vessels and Course of Ascending Aorta. In each case, by definition, the great vessels were transposed. Arising from the infundibular chamber the aorta ascended to be parallel with the more posteriorly located pulmonary trunk. The aortic valve was either in the same body plane as the pulmonary valve, or slightly cephalad to it. 
Where there was non-inversion of the infundibulum, the ascending aorta, after arising from the infundibular chamber at the right anterior base of the heart, was convex to the right (Fig. 4). In cases with non-inversion of the infundibulum, the external relation of the ascending aorta to the pulmonary trunk showed two main anatomical patterns. Of the 13 cases, 8 showed the aorta arising anteriorly and to the right of the pulmonary trunk in what might be termed an "oblique" relation; in the remaining 5, the ascending aorta lay directly anterior to the pulmonary trunk (Fig. 4).

In each of the 13 with infundibular inversion, the ascending aorta arose from the left anterior base of the heart. From this position, the ascending aorta showed two major courses and a minor third one. In the first and most common ( 7 of 13 cases) there was a distinct convexity of the ascending aorta towards the left (Fig. 5 , left). The second pattern ( 4 cases) showed the ascending aorta coursing directly vertically without any convexity to either side (Fig. 5, right). In the remaining 2 cases ascending aorta was convex to the right.

The external relation of the ascending aorta to the pulmonary trunk, as in the group with noninversion of the infundibulum, showed two anatomical patterns. Among 13 cases with inversion of the infundibular chamber, 5 showed the aortic origin anterior and to the left of the pulmonary trunk in an "oblique" relation (Fig. 5, left). In the remaining 8, the aortic origin was directly anterior to the pulmonary trunk (Fig. 5, right). It is important to note that the general arrangement of the great vessels in common ventricle with infundibular inversion was essentially similar to that observed in congenitally corrected transposition.

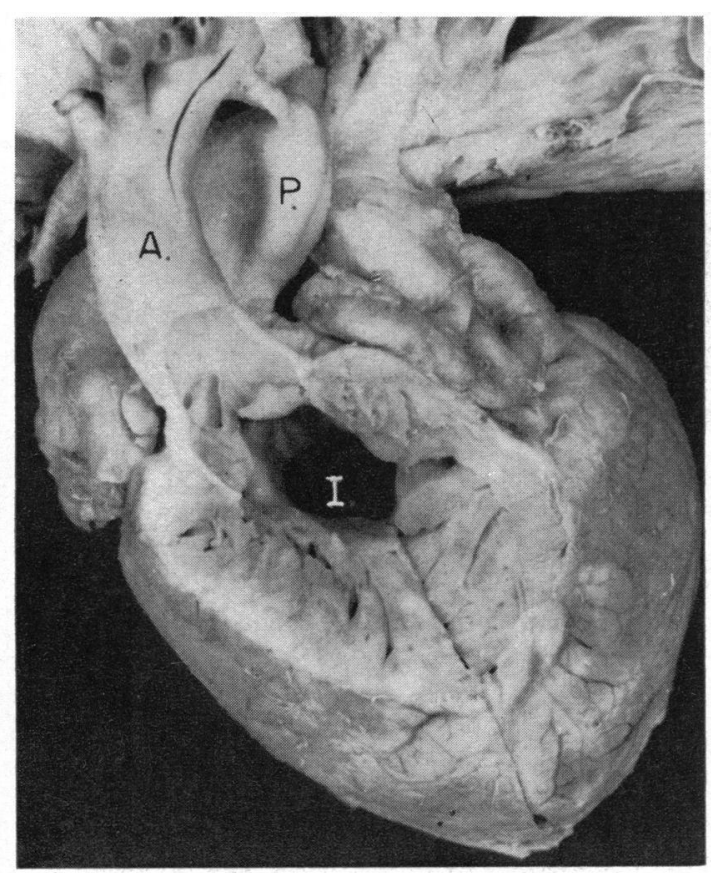

FIG. 4.-Common ventricle with transposition and non-inversion of the infundibulum. Specimen viewed from the front. The infundibular chamber (I) is located at the right anterior base of the heart in a non-inverted position. The transposed aorta (A), after arising from the infundibulum, shows a characteristic convexity towards the right. The origin of the wide pulmonary trunk $(P)$ lies directly behind that of the aorta and is obscured by it.
In 23 of 26 cases, the aortic arch passed normally over the left main-stem bronchus. In the remaining 3 , the aortic arch passed over the right main-stem bronchus as a right aortic arch. In 2, there was agenesis of the spleen; total situs inversus was present in one, while situs solitus existed in the other. In the third case, the heart was in the situs solitus position, there was noninversion of the infundibulum, and both $\mathrm{A}-\mathrm{V}$ valves were present.

Pulmonary Stenosis. Considering the entire series of 26 cases, regardless of the nature of the infundibulum, there were 14 without obstruction to pulmonary blood flow and 12 with some form of obstruction: this took the form of atresia at the pulmonary valve in some instances, while in others there was stenosis. Pulmonary stenosis was represented by (1) a stenotic bicuspid pulmonary valve alone, (2) a narrow subpulmonary muscular tract, or (3) a combination of the two foregoing conditions (Fig. 6).

The distribution of cases with obstruction to pulmonary flow was about equal in the group with infundibular inversion ( 7 of 13 cases) to that without inversion of the infundibulum $(5$ of 13 cases).

Atrio-ventricular Valves. Another important anatomical consideration among cases with common ventricle is the status of the $A-V$ valves. In the 26 cases, the anatomical arrangements of 


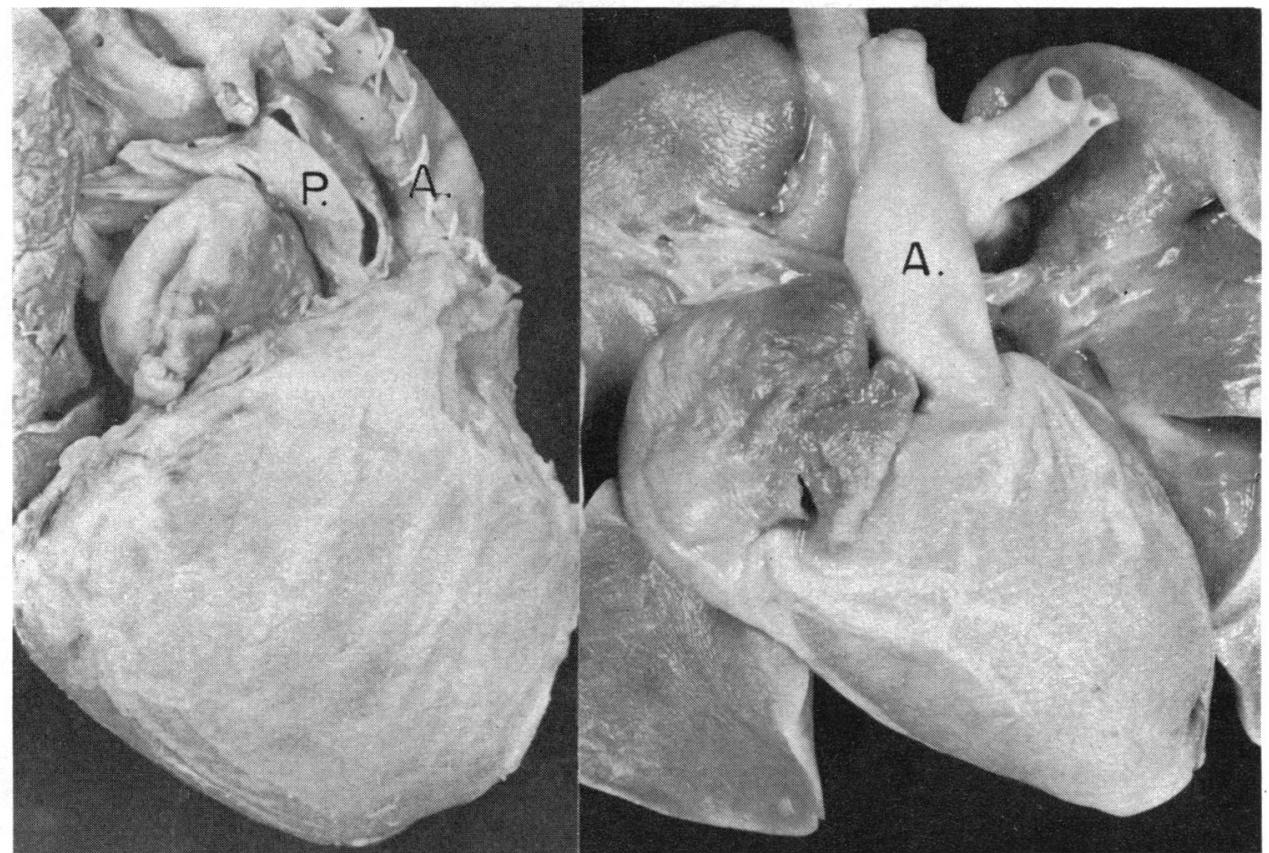

FIG. 5.-Two cases of common ventricle with transposition and inversion of the infundibulum. In both cases, the ascending aorta arises from the infundibulum which is at the left anterior base of the heart in an inverted position. The arrangements of the great vessels in relation to the base of the heart are similar to those in congenitally corrected transposition. Left. Anterior view showing the most common course exhibited by the aorta in cases with inversion of the infundibulum. The ascending aorta (A) shows a distinct convexity toward the left, and is situated anterior and to the left of the pulmonary trunk (P). Right. Anterior view showing the second most common course exhibited by the aorta when the infundibulum is inverted. The ascending aorta (A) courses directly upward. The posteriorly lying pulmonary trunk is directly behind the aorta and is obscured in this view.

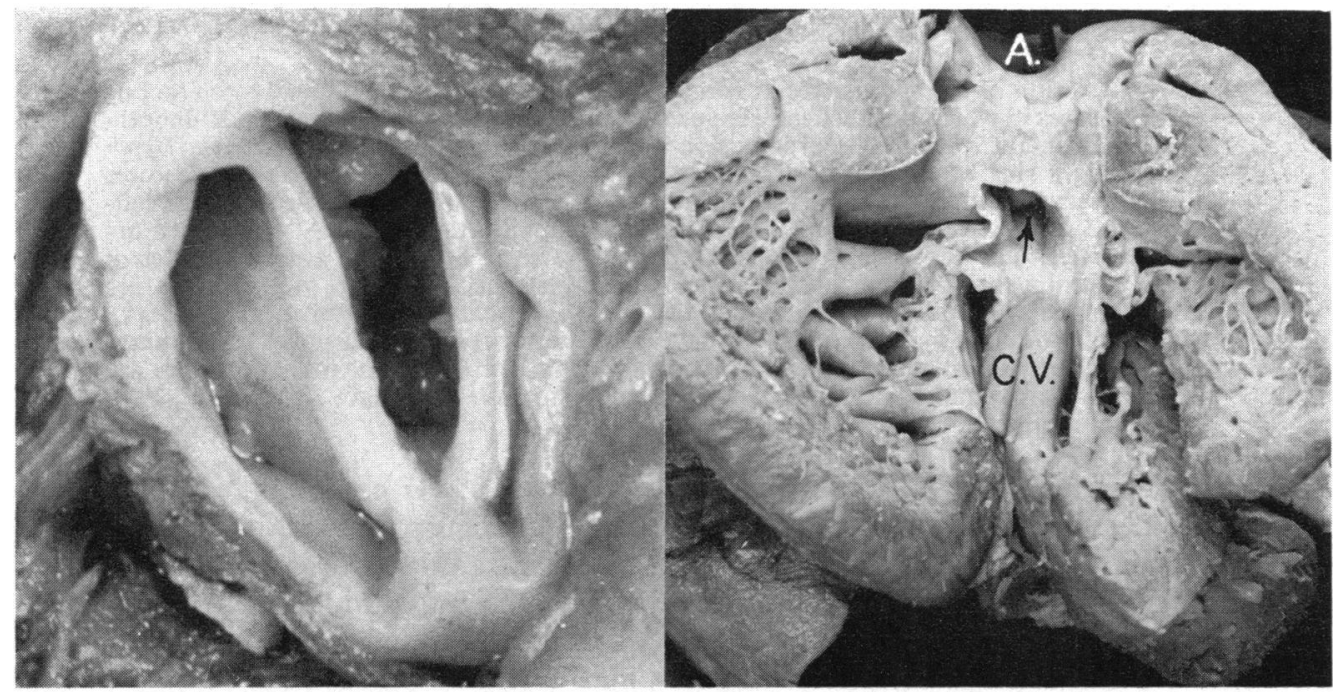

FIG. 6.-Variations in obstruction to pulmonary flow as observed in 2 cases of common ventricle with transposition. Left. Stenotic pulmonary valve viewed from above in a case in which there was non-inversion of the infundibulum and both A-V valves were present. The pulmonary valve is bicuspid with thickening of the cusps. There is fusion of the valve leaflets at the posterior commissure. Right. Narrow subpulmonary tract (point of arrow) as viewed from within the common ventricle (CV). The transposed aorta (A) arises from the inverted infundibulum. Both A-V valves are present. The pulmonary valve (not shown) was stenotic. 


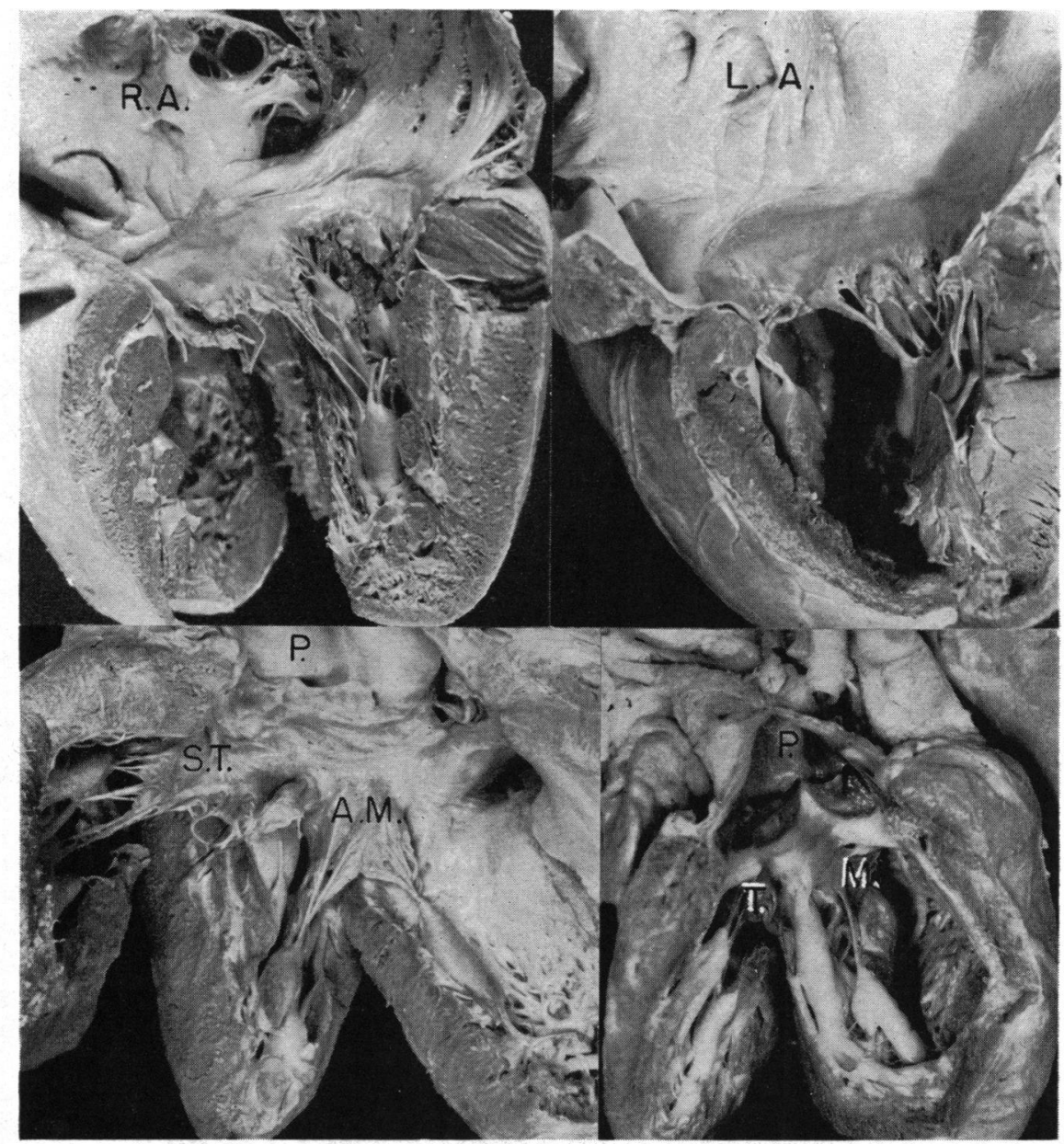

FIG. 7.--Relation of the A-V valves in common ventricle with transposition as seen among the 11 cases in which both valves were present. Upper and lower left: from a 20-monthold male infant. Infundibular inversion was present in the 2 cases illustrated. Upper left. Right side of the heart. The right-sided A-V valve shows the essential features of a tricuspid valve. RA = right atrium. Upper right. Left side of heart. The leftsided $A-V$ valve shows the essential features of a mitral valve. $L A=$ left atrium. Lower left. The septal leaflet of the tricuspid valve (ST) and the anterior leaflet of the mitral valve (AM) are continuous with each other. In turn, both leaflets are continuous with pulmonary valvular tissue. $\mathbf{P}=$ pulmonary trunk. Lower right. Case of 4-day-old male infant. Uncommon relation between tricuspid $(T)$ and mitral (M) valves as neither valve is continuous with the other. Also, the A-V valves are separated from pulmonary valvular tissue by a horizontal column of muscle. $\mathbf{P}=$ pulmonary trunk.

the A-V valves could be divided into 4 categories as follows: (1) common A-V valve (3 cases), (2) both tricuspid and mitral valves present (11 cases), (3) tricuspid atresia with an intact mitral valve ( 7 cases), and (4) mitral atresia with an intact tricuspid valve ( 5 cases). When A-V valves were present, regardless of inversion or non-inversion of the infundibulum, the right-sided valve showed the essential structure of a tricuspid valve, and the left-sided valve that of a mitral valve (Fig. 7, upper left and upper right). In such cases, inasmuch as no ventricular septum was present, there was continuity of the basal aspects of the septal tricuspid and anterior mitral leaflets (Fig. 7, 

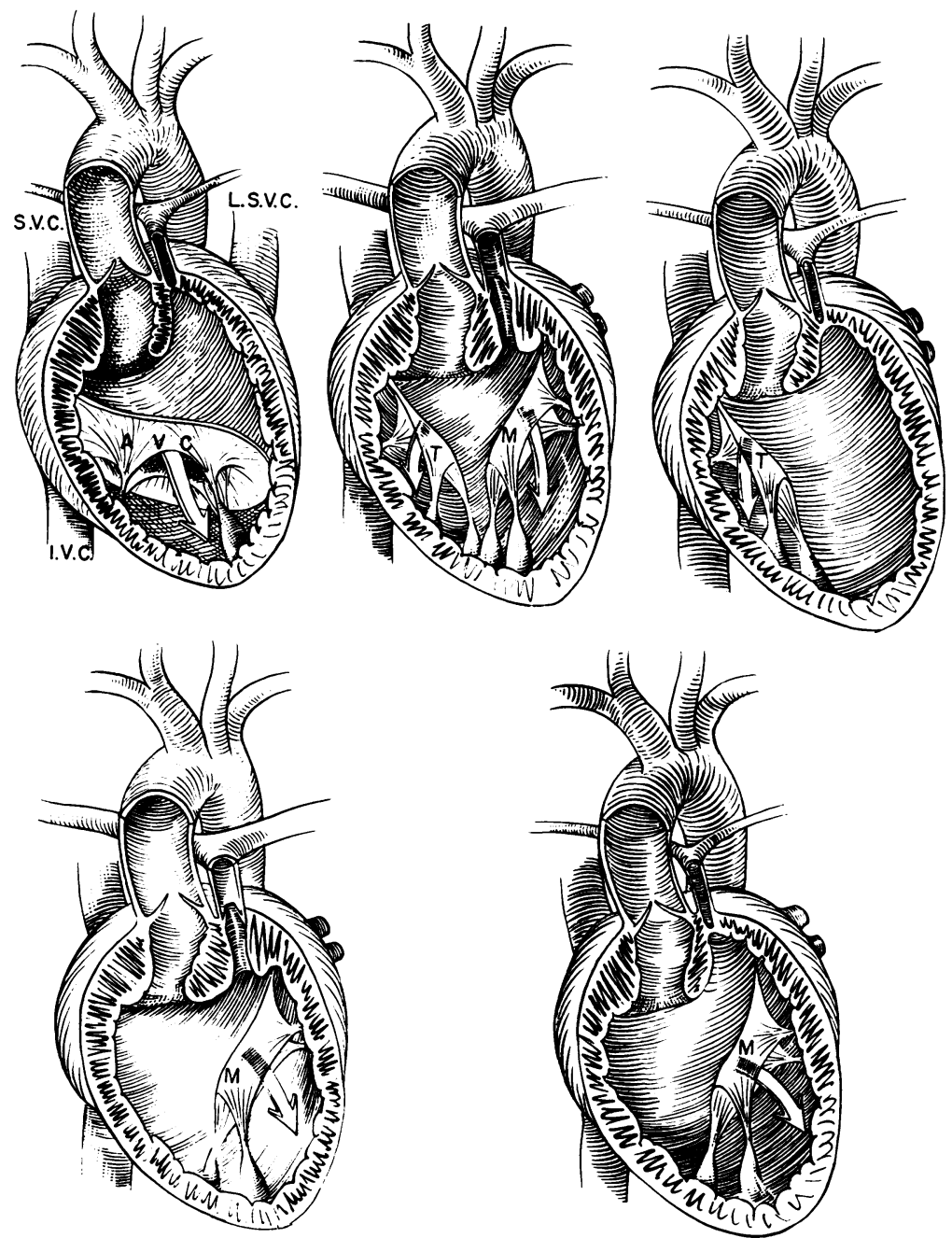

Fig. 8.-Common ventricle with transposition, non-inversion of infundibulum, and obstruction to pulmonary flow. Condition of A-V valves as seen in 5 cases. Upper left. Pulmonary atresia, common A-V valve (AVC) (1 case). Bilateral superior venæ cavæ (S.V.C.; L.S.V.C.) were present. IVC = inferior vena cava. Upper centre. Combined subpulmonary and pulmonary valvular stenosis. The tricuspid $(\mathrm{T})$ and mitral $(\mathrm{M})$ valves are each present (1 case). Upper right. Pulmonary atresia and mitral atresia (1 case). Lower left. Pulmonary stenosis and tricuspid atresia (1 case). Lower right. Pulmonary atresia and tricuspid atresia (1 case).

lower left). Usually the conjoined A-V tissue was continuous with tissue of the transposed (posteriorly lying) pulmonary valve (Fig. 7, lower left).

Less commonly the A-V valvular tissue was separated from the pulmonary valve by a horizontal ridge of muscle (Fig. 7, lower right). As the aortic valve lay in an anterior transposed position, in no case was there close proximity between $\mathrm{A}-\mathrm{V}$ and aortic valvular tissues.

It was considered of interest to review the pattern of the A-V valves with the state of the infundibulum, on one hand, and with the question of obstruction to pulmonary flow, on the other.

Non-inversion of Infundibulum with Obstruction to Pulmonary Flow (Fig. 8). Among the 5 cases of non-inversion of the infundibular chamber with obstruction to pulmonary flow, there was no prevailing pattern for the $\mathrm{A}-\mathrm{V}$ valves. A common $\mathrm{A}-\mathrm{V}$ valve was observed in 1 case (with 

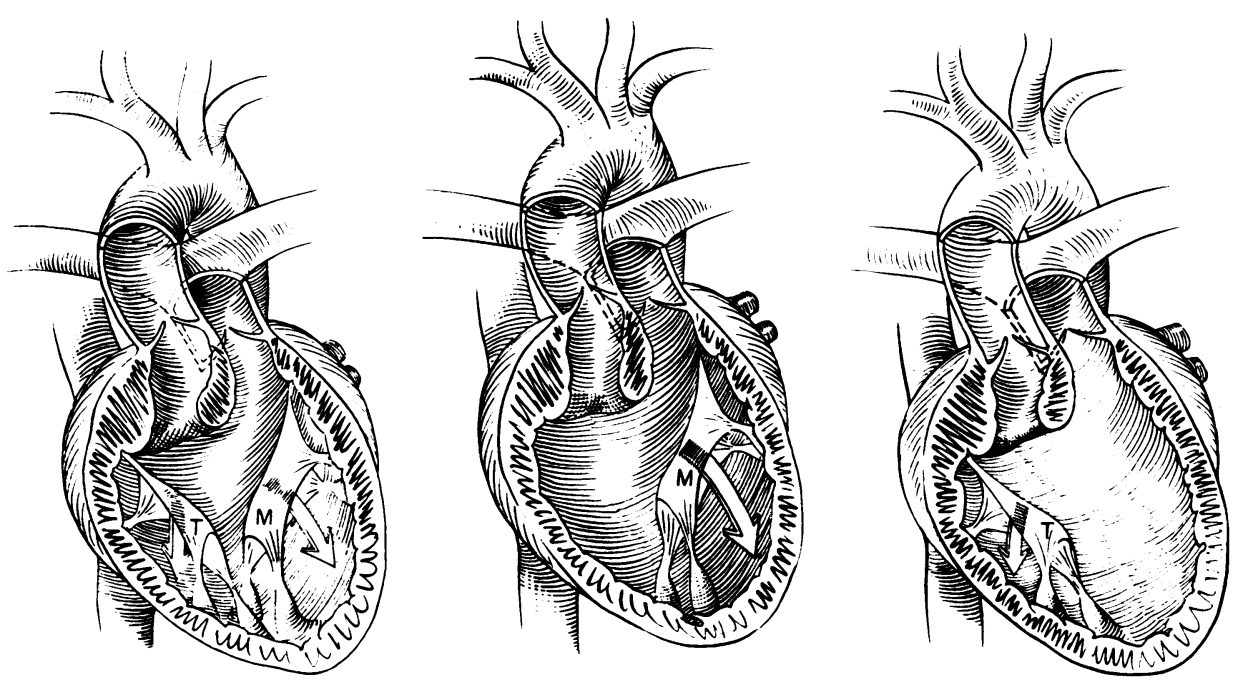

FIG 9.-Common ventricle with transposition, non-inversion of the infundibulum, and no obstruction to pulmonary flow. Abbreviations as in Fig. 8. Condition of A-V valves in 8 cases. Left. Both A-V valves present (3 cases). Centre. Tricuspid atresia (3 cases). Right. Mitral atresia ( 2 cases).

agenesis of the spleen); both $\mathrm{A}-\mathrm{V}$ valves were present in one case; and there was coexistent atresia of the mitral and pulmonary valves in 1 case and tricuspid atresia in the remaining 2 cases, in one of which there was pulmonary stenosis, and in the other, pulmonary atresia.

Non-inversion of the Infundibulum without Obstruction to Pulmonary Flow (Fig. 9). Among the 8 cases of non-inversion of the infundibular chamber without obstruction to pulmonary flow, there again was no prevailing pattern for the $\mathrm{A}-\mathrm{V}$ valves. In 3 both $\mathrm{A}-\mathrm{V}$ valves were present, in 3 there was tricuspid atresia, and in 2, mitral atresia. Common A-V valve was not seen in this sub-group.

Inversion of the Infundibulum with Obstruction to Pulmonary Flow (Fig. 10). In the 7 cases of inversion of the infundibular chamber with obstruction to pulmonary flow, there were two prevailing patterns, namely common $\mathrm{A}-\mathrm{V}$ valve and the one in which both A-V valves were present. Atresia of either A-V valve was uncommon in this category of cases. A common A-V valve was observed twice (pulmonary atresia in 1 ; pulmonary stenosis in 1) and A-V valves were present in each of 3 other cases (pulmonary atresia in 1; subpulmonary and pulmonary valvular stenosis in 2). The sixth case showed tricuspid atresia and subpulmonary stenosis, while in the seventh, mitral atresia and pulmonary atresia coexisted.

Inversion of the Infundibulum without Obstruction to Pulmonary Flow (Fig. 11). Among 6 cases of inversion of the infundibular chamber without pulmonary stenosis, 4 had both A-V valves present, one showed tricuspid atresia, and the other mitral atresia.

Additional Anomalies. Besides the above frequently occurring anomalies, in association with single ventricle, there were, among the 26 cases, a variety of other infrequently occurring anomalies. A patent ductus arteriosus was present in 12 cases. The relative incidence involving cases with inversion or non-inversion of the infundibulum was approximately equal. The most striking association with an open ductus arteriosus was seen among cases with pulmonary atresia. In each of the 6 cases with atresia of the pulmonary valve, the ductus arteriosus was patent. In one case having inversion of the infundibulum with pulmonary atresia and intact atrio-ventricular valves, bilateral patent ducti were observed.

In 23 cases, there was either a valvular competent patent foramen ovale or an atrial septal defect of the fossa ovalis type. In 13 of these, a small atrial septal defect (maximum diameter, $7 \mathrm{~mm}$.) was 

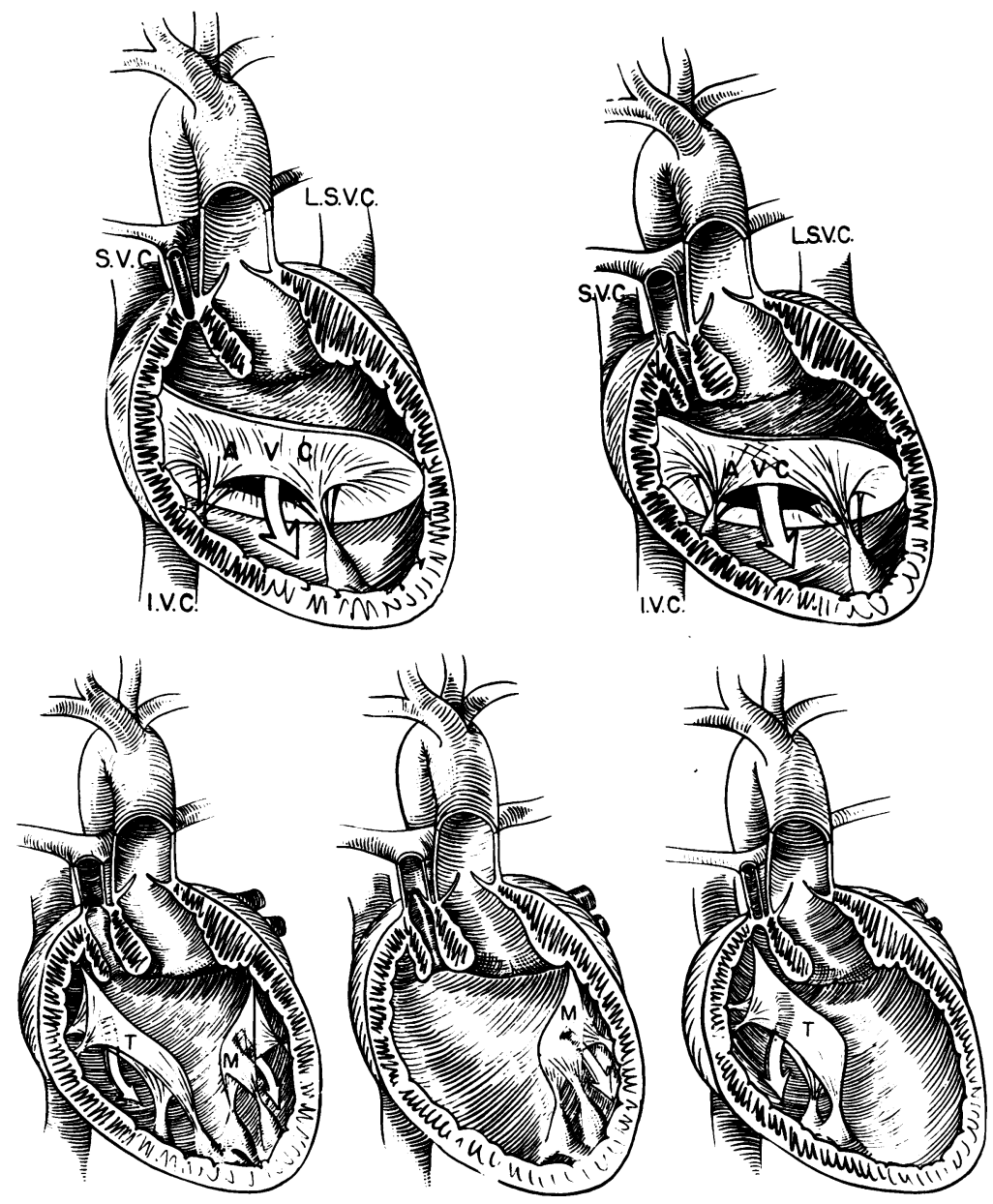

FIG. 10.-Common ventricle with transposition, inversion of the infundibulum, and obstruction to pulmonary flow. Abbreviations as in Fig. 8. Condition of A-V valves as seen in 7 cases. Upper left. Pulmonary atresia, common A-V valve (1 case). Bilateral superior venæ cavæ were present. Upper right. Pulmonary stenosis, common A-V valve (1 case). Bilateral superior venæ cavæ were present. Lower left. Pulmonary stenosis and both A-V valves present $(2$ cases). (The case of pulmonary atresia and both A-V valves present is not illustrated.) Lower centre. Subpulmonary stenosis and tricuspid atresia (1 case). Lower right. Pulmonary atresia and mitral atresia (1 case).

present. In 3 (each with a common $\mathrm{A}-\mathrm{V}$ valve and agenesis of the spleen), the atrial septum was represented only by a thin remnant of septal tissue. Conceivably, the opening above the remnant of tissue could be considered an atrial septal defect of the fossa ovalis type, whereas the opening below the tissue remnant could be considered "ostium primum" type of defect: this formation has usually been called a "common atrium". Since the ventricular septum was absent and the atrial portion was considered a common atrium, the condition in these 3 cases may be termed cor biloculare.

In one case of cor biloculare, there was non-inversion of the infundibulum, pulmonary atresia and total anomalous pulmonary venous connexion to the superior vena cava (Fig. 12, left). Each of the remaining 2 cases of cor biloculare showed inversion of the infundibulum. In one, the pulmonary 

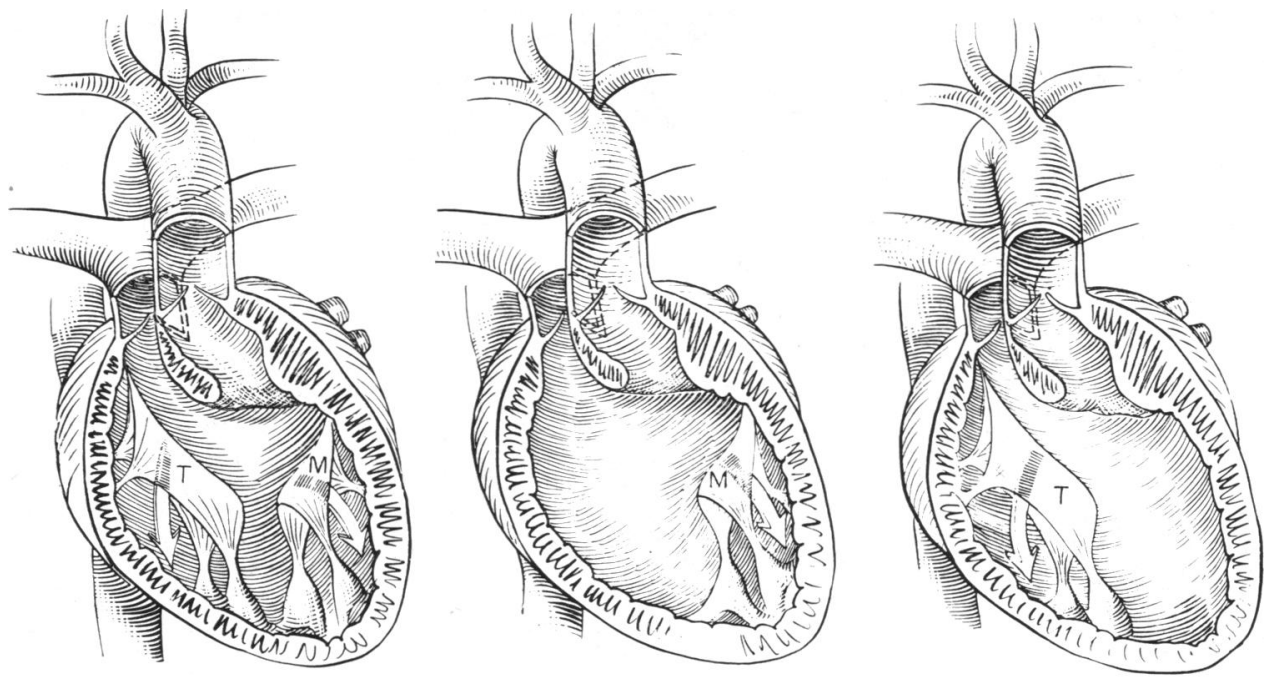

FIG. 11.-Common ventricle with transposition, inversion of the infundibulum, and no obstruction to pulmonary flow. Abbreviations as in Fig. 8. Condition of A-V valves in 6 cases. Left. Both A-V valves present (4 cases). Centre. Tricuspid atresia (1 case). Right. Mitral atresia (1 case).

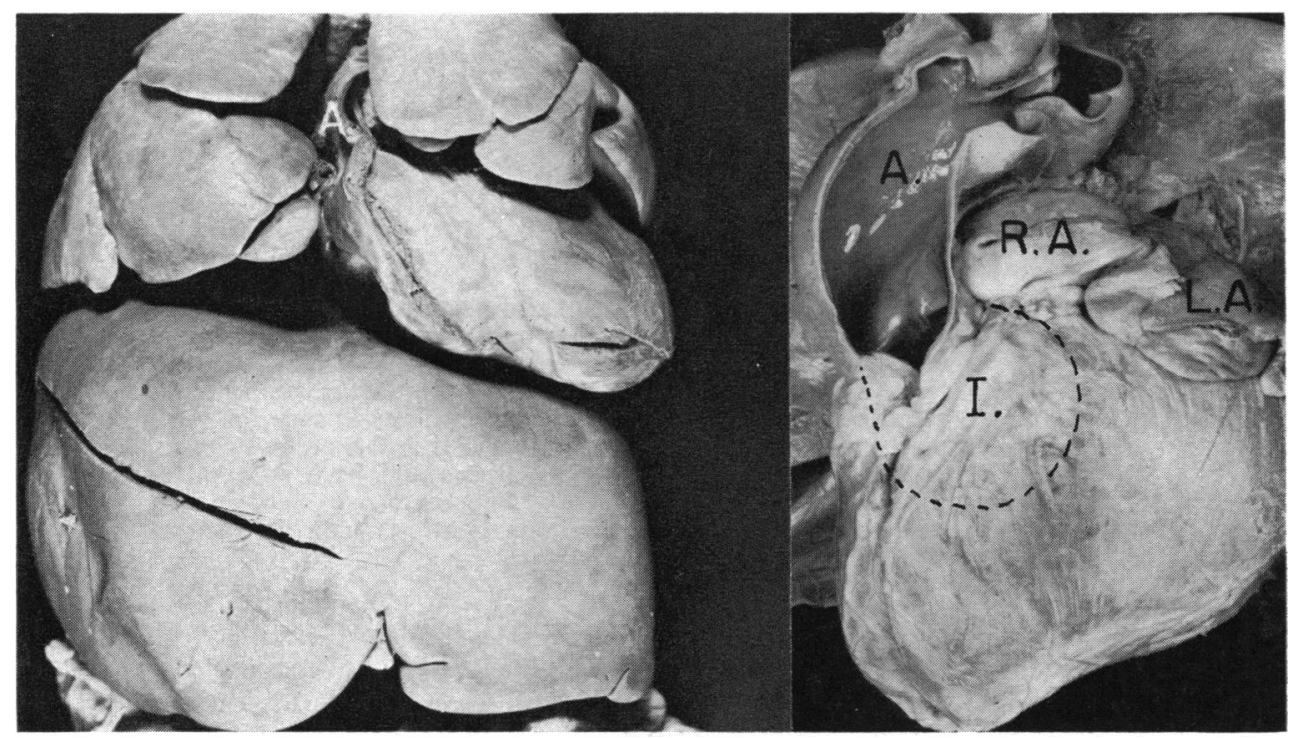

FIG. 12.-Left. Thoracic organs and liver from a case of common ventricle with transposition. The aorta (A) arises from a non-inverted infundibulum. Also present were a "common atrium", pulmonary atresia, and agenesis of spleen. Symmetrical liver is part of the developmental complex of agenesis of spleen. (From Lucas et al., 1962. Reproduced with permission of the American Heart Association.) Right. Anterior view of heart in a case of common ventricle with transposition and non-inversion of the infundibulum ( $I$; dotted line represents outline of infundibulum). The cardiac apex is directed toward the right. To the left of the transposed aorta (A) lie both atrial appendages (RA; LA) representing juxtaposition of the atrial appendages. 
valve was stenotic, and pulmonary veins terminated in the side of the common atrium. In the other case, the pulmonary valve was atretic, the right pulmonary veins connected with the right side of the common atrium, and the left pulmonary veins connected to the left side of the common atrium.

No example of anomalous pulmonary venous connexion occurred except in the 3 with cor biloculare, each of which was associated with agenesis of the spleen.

Juxtaposition of the atrial appendages was seen in 3 cases (Fig. 11, right): in each, both atrial appendages lay to the left of the great vessels, and tricuspid atresia with non-inversion of the infundibulum was present. Obstruction to pulmonary flow occurred in two.

Coarctation of the aorta between the left common carotid and left subclavian arteries was seen in one, a case with tricuspid atresia and non-inversion of the infundibulum. In a case with mitral atresia and non-inversion, tubular hypoplasia of the aortic arch involved the segment of aorta between the left subclavian artery and ductus arteriosus. There was no obstruction to pulmonary flow in either case.

In 2 of the 26 specimens, the cardiac apex was on the right side. In one, the organs were in situs solitus location and the heart showed non-inversion of the infundibulum, tricuspid atresia, and pulmonary stenosis (Fig. 12, right). In the other with a right-sided cardiac apex, there was total situs inversus and asplenia.

Two major patterns were exhibited by the coronary arteries. In those without inversion of the infundibulum, the artery arising in the left anterior position gave rise to the anterior descending and circumflex arteries, while the second artery arose in a right posterior position and coursed

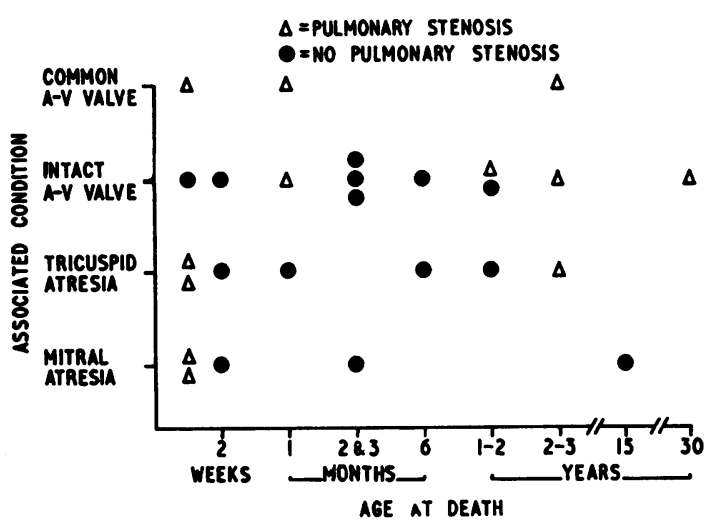

FIG. 13.-Age at death in 26 patients with common ventricle and transposition of the great vessels according to associated conditions at the atrio-ventricular valves. as a right coronary artery. Among the 13 cases with inversion of the infundibulum the coronary arterial pattern in 9 was like that already mentioned; in the remaining 4 the coronary arterial pattern was a mirror image of that described: the anterior descending coronary artery arose from the same vessel that proceeded into the right atrio-ventricular sulcus; the artery arising from the left anterior aspect of the aorta coursed simply as a left circumflex artery.

Sex, and Age at Death. Common ventricle was strongly associated with the male sex: in the 26 cases with this condition there were 20 male and 6 female cases. The sex distribution in the 14 cases without pulmonary stenosis was approximately equal to that in the 12 cases with obstruction to pulmonary flow.

There was no connexion between anatomical pattern, in particular the atrio-ventricular valves and the state of pulmonary blood flow (Fig. 13), and age at death. Most of the patients died during infancy. The two oldest were a 15-year-old boy with mitral atresia and without pulmonary stenosis and a 30-year-old man with pulmonary stenosis and with both A-V valves present.

\section{DISCUSSION}

When a common ventricle occurs it is rare that the great vessels are not transposed. Among somewhat over 800 specimens of congenital cardiac disease among the pathological collections of the University of Minnesota and the Cardiovascular Registry of The Charles T. Miller Hospital, there are only 4 cases of common ventricle without transposition but with pulmonary stenosis ( 3 of 
these studied by Elliott et al., 1963a), while 26 cases of common ventricle with transpostion are present. These 26 cases formed the basis for this study. Thus, among cases of common ventricle with transposition of the great vessels, certain conditions are commonly associated: these include pulmonary stenosis or atresia, and atresia of one of the A-V valves.

Clinical recognition of the foregoing points may be difficult, but not impossible. It is hoped that this anatomical analysis of common ventricle will serve as a guide to the clinician, and that it will emphasize the possibility of occult lesions: in particular, with common ventricle, coexistent and occult mitral atresia.

A possible clue to the diagnosis of tricuspid atresia with common ventricle may come from identification of juxtaposition of the atrial appendages. In this series, each of the 3 cases with this condition exhibited tricuspid atresia also, for we have observed juxtaposition of the atrial appendages in 2 of 60 cases of complete transposition (Elliott et al., 1963b). It will be recalled that our 3 cases of juxtaposition with tricuspid atresia occurred in a group of only 7 cases of tricuspid atresia with common ventricle and transposition.

Among cases of congenital heart disease in which it is known that the great vessels are transposed, a common condition is complete transposition. This entity is to be distinguished from common ventricle with transposition, since in complete transposition there are two ventricles, the aorta arises exclusively from the right ventricle, and the pulmonary trunk arises exclusively from the left ventricle. Earlier teachings indicated that in complete transposition, the aorta commonly lay directly anterior to the pulmonary trunk. Our recent observations (Elliott et al., 1963b) have indicated that this position is exceptional; it was observed in only 2 of 60 cases of complete transposition. Thus, the observation that the aorta is situated directly anterior to the pulmonary trunk favours a diagnosis of a condition other than complete transposition: one of the probabilities is common ventricle, the other is congenitally corrected transposition.

Congenitally corrected transposition is an established entity in which two ventricles are present (a ventricular septal defect may be associated). In this condition the left-sided ventricle, i.e. the arterial ventricle, resembles a normal right ventricle, and through an inverted infundibulum gives rise to the aorta. It is apparent that, at the basal aspect of the heart, the relations in corrected transposition are like those in common ventricle with infundibular inversion. For this reason some would group together corrected transposition, and common ventricle, with transposed great vessels and infundibular inversion. We believe that there are important differences anatomically, functionally, and surgically between the two. Corrected transposition has two ventricles and two A-V valves and, except for associated anomalies, the heart could function normally. On the other hand, common ventricle itself is an anomaly with obvious fundamental differences from a situation in which two ventricles are present. Moreover, when a common ventricle is present, atresia of either $\mathrm{A}-\mathrm{V}$ valve may coexist.

It has been suggested by some that an anatomical gradation exists between ventricular septal defect and common ventricle. We have not observed such gradations. In cases with both A-V valves present, the two valves clearly open either into (1) a common ventricular chamber (from which an infundibulum gives rise to the aorta), or (2) one valve leads to a right-sided ventricular chamber while the other leads to a left-sided ventricular chamber. The absence of entrance of an A-V valve into the infundibulum of the common ventricle is important evidence favouring the view that the infundibulum is a subdivision of the common ventricle rather than a separate ventricle.

\section{SUMMARY}

This report is based on the anatomical study of 26 cases of common ventricle with transposition of the great vessels. These cases were among a collection of about 800 specimens of major malformations of the heart or great vessels.

In each specimen the aorta arose from an infundibular chamber located at the basal aspect of the heart anteriorly. The cases were divided into 2 groups depending upon the site of the infundibulum. When the position of the infundibulum approached that of the right ventricular 
infundibulum of normal hearts, it was considered to be "non-inverted": half of the cases fell into this group; in the other half, the infundibulum was in an inverted position.

Abnormalities that were additional to common ventricle, with transposition, were found in some. These included pulmonary stenosis or atresia (12), common A-V valve (3), mitral atresia (5), and tricuspid atresia (7). In 11 cases, both $\mathrm{A}-\mathrm{V}$ valves were present. In the conditions involving the $A-V$ valves there were about 50 per cent with non-inversion and 50 per cent with inversion of the infundibulum.

In each of the 3 cases with common A-V valve there was agenesis of the spleen and a "common atrium".

Three cases showed juxtaposition of the atrial appendages; in each there was tricuspid atresia and non-inversion of the infundibulum.

\section{REFERENCES}

Abbott, M. E. (1936). Atlas of Congenital Cardiac Disease, p. 50. American Heart Association, New York.

Campbell, M., Reynolds, G., and Trounce, J. R. (1953). Six cases of single ventricle with pulmonary stenosis. Guy's Hosp. Rep., 102, 99.

Edwards. J. E. (1960). Congenital malformations of the heart and great vessels. In Pathology of the Heart, 2nd ed., ed. S. E. Gould, p. 335. Thomas, Springfield, Illinois.

Elliott, L. P., Amplatz, K., Anderson, R. C., and Edwards, J. E. (1963a). Cor triloculare biatriatum with pulmonary stenosis and normally related great vessels. Clinico-pathologic observations in three cases. Amer. J. Cardiol., $11,469$.

, Neufeld, H. N., Anderson, R. C., Adams, P., Jr., and Edwards, J. E. (1963b). Complete transposition of the great vessels. An anatomic study of sixty cases. Circulation, 27, 1105.

Favorite, G. O. (1934). Cor biatriatum triloculare with rudimentary right ventricle, hypoplasia of transposed aorta, and patent ductus arteriosus, terminating by rupture of dilated pulmonary artery. Amer. J. med. Sci., 187, 663.

Harley, H. R. S. (1958). The embryology of cor triloculare biatriatum with bulbar (rudimentary) cavity. Guy's Hosp. Rep., $107,116$.

Heath, D. (1957). Cor triloculare biatriatum. Circulation, 15, 701.

Lev, M., Alcalde, V. M., and Baffes, T. G. (1961). Pathologic anatomy of complete transposition of the arterial trunks. Pediatrics, 28, 293.

Lucas, R. V., Jr., Neufeld, H. N., Lester, R. G., and Edwards, J. E. (1962). The symmetrical liver as a roentgen sign of asplenia. Circulation, 25, 973 .

Rogers, H. M., and Edwards, J. E. (1951). Cor triloculare biatriatum: an analysis of the clinical and pathologic features of nine cases. Amer. Heart J., 41, 299.

Spitzer, A. (1951). The Architecture of Normal and Malformed Hearts, ed. M. Lev, and A. Vass, p. 64. Thomas, Springfield, Illinois.

Taussig. H. B. (1960). Congenital Malformations of the Heart, Vol. 2: Specific Malformations, 2nd ed., p. 325. Harvard University Press, Cambridge, Massachusetts. 